\title{
The Heian-kyo Site's Database and Platform: Their Construction and Utilization
}

\author{
Mikiharu TAKEUCHI $^{\mathrm{a}}{ }^{*}$, Keiji YANO ${ }^{\mathrm{a}}$ \\ ${ }^{a}$ Ritsumeikan University, Japan, gr0465ip@ed.ritsumei.ac.jp, yano@lt.ritsumei.ac.jp \\ * Corresponding author
}

Keywords: WebGIS, Heian-kyo, archaeological site, excavation, open data, Kyoto

\begin{abstract}
:
In recent years, WebGIS available through the Internet has become popular among the general public. It had been applied in the field of archaeology and buried cultural properties, for example, by converting archaeological site maps and kofun (ancient tomb) databases into WebGIS and making them available on the Internet. In this study, we aim to create a database of excavation records of the Heian-kyo site, an ancient capital of Japan, and make it available on the WebGIS platform. In addition, we will discuss how the database can be utilized. Since it makes it possible to view all the records of excavations up to now on a single platform, that will greatly contribute not only to better understanding of the Heiankyo site but also to the administration of buried cultural properties in the future.
\end{abstract}

Heian-kyo was the capital of Japan for more than 1,000 years from 794. Within its area, approximately $23.4 \mathrm{~km} \mathrm{~m}^{2}$ in size, more than 10,000 excavations have been carried out in various forms since the early postwar years. Recently, the number of rescue excavations has greatly exceeded that of academic excavations in Japan, and the Heian-kyo site is no exception. In particular, where the Heian-kyo site was located has been urbanized, and a lot of redevelopment has taken place. Therefore, rather than archaeological purposes that could be well-planned ahead, social factors of land development and buried cultural property administration have often led to excavations. In order to manage and publish the survey records of such excavations, it is effective to digitize and construct GIS databases.

In this term, Nagata (2002) of the Kyoto City Archaeological Research Institute created a database of excavation records related to the Heian-kyo site. In addition, Nagamune (2019) of Kyoto Asny has advocated the need to build an open information infrastructure for the site, digitizing and compiling plans created during excavations. Based on the information from these data, Ritsumeikan University has built a WebGIS by using ArcGIS Hub of ESRI's ArcGIS Online. ArcGIS Hub can easily build an open data site for sharing data, and viewers can download registered data in a variety of geospatial information file formats such as GeoJSON, KML, and CSV. In the field of archaeology, where the use of open data has been progressing in recent years, we assume that this kind of open data-specific system will present an advanced case.

Figure 1 shows an image (left) of the platform under construction, and an example of enlarged plan (right). The top page includes a map to show plans and their locations. Here, Figure 1 shows the area around Nijo Station, one of the most developed areas of the Heian-kyo site. A database user can enlarge any plan to a resolution, large enough to read the layout of the remains on it. This plan is given the coordinates based on the survey done during the excavation. Moreover, its metadata includes: the year of excavation, the survey organization, the title of the report, and an outline of the excavation. In Japan, more excavation reports have become open to the public, many of which are available through the Internet, with the Comprehensive Database of Archaeological Site Reports in Japan as one of the most representative ones. By incorporating URLs of these reports as attributes, we are creating an environment where detailed information on excavations are easily accessible. By visualizing multiple survey plans from past excavations on a map, we expect that it will be much easier for the user to see positional relationship of the remains. Thus, we can expect this system to serve as a foundation for promoting archaeological research on the Heian-kyo site, with a vast amount of excavation results. In addition, as the user can know the specific excavation sites, the system would be useful in preliminary discussions and communications for future development and excavation. 


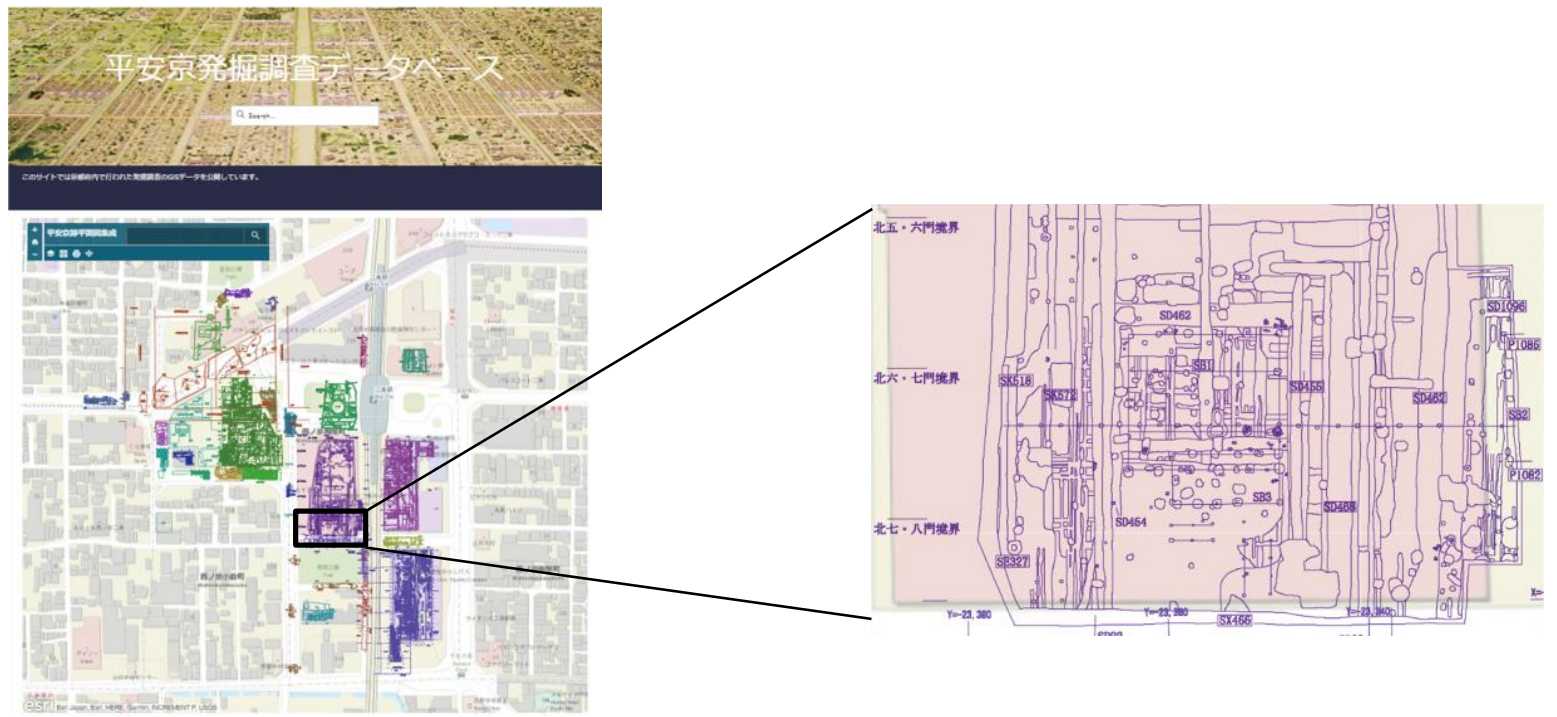

Figure 1. Platform (beta version) using ArcGIS Hub for releasing the Heian-kyo site's database (left) and enlarged plan view (right).

Furthermore, we display the locations of the excavations from the Heian-kyo site's database as points on the maps for every decade for the 1970s, 1980s, and 1990s (Figure 2). Here, the maps also show the distribution density by Kernel density estimation and the Heian-kyo's square-grid pattern. In these three periods, Heian-kyu (the Heian Imperial Palace), located north of the center of the Heian-kyo site, has a particularly large number of excavations. Heian-kyu was not only the imperial residence but also where state ceremonies were held, and since the Kyoto City recognizes this area as an important archaeological site, it conducted many excavations. In the 1970s, many excavation sites were lined up in a straight line along Karasuma Street. This is a result of a series of excavations associated with the city's subway construction, and clearly shows that these sites were selected due to social factors, namely urban development. Although the sites were destroyed by the construction, the survey results of the excavations under the subway running north-south at the Heian-kyo site were of great use in archaeology. Interpreting these sites from a social perspective and examining the excavation results and the ways in which the sites were treated will give us an important perspective for future site management and research.

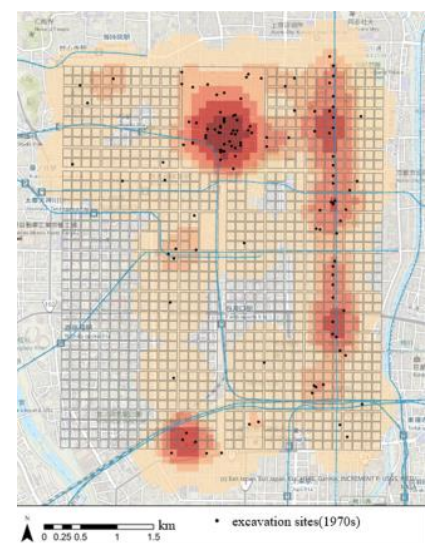

1970 s

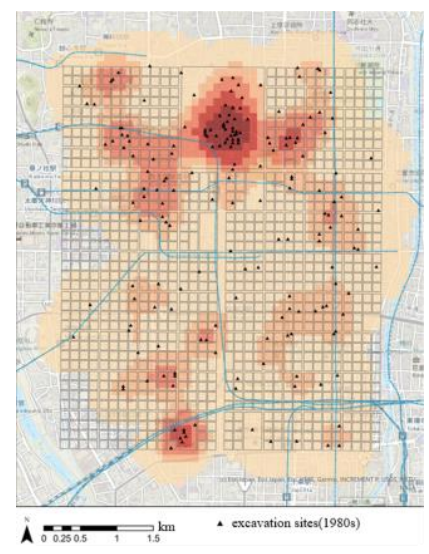

$1980 \mathrm{~s}$

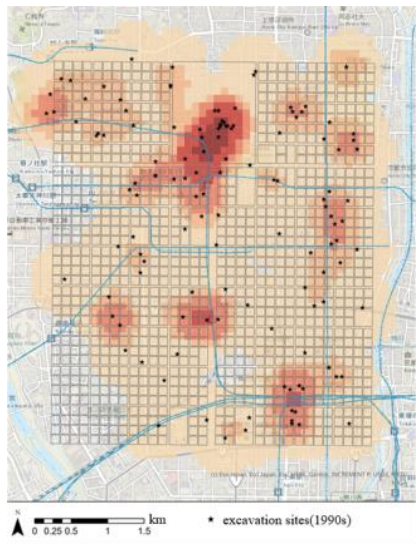

distribution density $\leq 0$

$\leq 10$

$\leq 20$

$\leq 40$

$\leq 80$

$\leq 149.445831$

Figure 2. The distribution of excavations within the Heian-kyo site (1970s, 1980s, and 1990s).

In the future, we need to enrich the contents to make the excavation results more useful for education and dissemination to the general public, which includes a system that allows users to view photos of the remains and excavation sites, and a function that displays unearthed sites of each artifact. Therefore, we will continue to develop this platform for archaeological research, communication in the buried cultural property administration, and education and dissemination about the Heian-kyo site. 